\title{
EFFICACY OF INTRA-ARTICULAR ANALGESIC INJECTION VERSUS FEMORAL NERVE BLOCK FOR PAIN RELIEF AFTER TOTAL KNEE ARTHROPLASTY
}

Watcharin Panichcharoen, Luckkana Srithongpim, Wanwipa Arunmanee, Nattawud Rodchom

Department of Orthopedic Surgery, Somdechphrapinklao Hospital, Bangkok, Thailand

\begin{abstract}
This is a quasiexperimental research which objectives are to study efficiency of intra-articular analgesic injection and compare efficiency for pain relief between intra-articular analgesic injection and femoral nerve block in total knee arthroplasty at SomdechPhrapinklao hospital. 40 patients with operated total knee arthroplasty, randomised to 2 groups (20 patients). Control group received femoral nerve block, another group received intra-articular injection.

Both groups receive spinal morphine nerve block, operated by same surgeon, same surgical technique and same kind of implant. After surgery all patients record VAS score at 1,3,6,12,24,48 hours, doses of injection and oral analgesic drug, degree of knee flexion and hospital stay. Statistics used percentage, mean, standard deviation and independent $t$-test. We found patients received intra-articular analgesic injection had lower VAS pain score, lower dose analgesic drug than patients who received femoral nerve block and more knee flexion postoperatively in statistic significantly. And both Intra-articular analgesic injection and femoral nerve block can decrease VAS pain score, decrease dose analgesic drug postoperatively and improved knee flexion suitable for guideline pain relief in total knee arthroplasty.
\end{abstract}

Keywords : Intra-articular analgesic injection, Femoral nerve block, Total knee arthroplasty, Pain relief

J Southeast Asian Med Res 2017; 1: 1-5.

http://www.jseamed.org

\section{Correspondence to:}

Panichcharoen W, Department of Orthopedic Surgery, Somdechphrapinklao Hospital, Bangkok Thailand

E-mail : watcharinpa@hotmail.com 


\section{Introduction}

Osteoarthritis of knee is a major medical problem health in Thailand. It was topten most common disease in elders and incidence $10 \%$ of elders more than 55 years old.

In severe stage patients must go total knee arthroplasty for pain relief and improved quality of life. In 2013, 200 patients operated total knee arthroplasty in Somdejphrapinklao hospital. Postoperative pain was a major problem due to delay normal diary activities. Spinal morphine analgesic was standard regimen for all patients. But most patients still severe pain and need more additional analgesic drug such as femoral nerve block.

Lamplot JD et al and Vandittoli PA et al report efficiency and rapid recovery time of additional intraarticular analgesic drug same as Toftdahl et al.

But Tanikawa et al found equal efficiency between intra- articular analgesic and femoral nerve block.

Szczukowski MJ et al found good efficiency of femoral nerve block but Widmer BJ et al shows same efficiency of femoral nerve block and non-femoral nerve block.

In Thailand Yuenyongviwat $\mathrm{V}$ et al report good efficiency of intra-articular analgesic drug but Panichkul et al found no efficiency of intra-articular analgesic drug.

Many reports had many results and controversy. Then this study compare efficiency between intraarticular analgesic and femoral nerve block and create guideline pain relief of total knee arthroplasty.

\section{Objectives}

1) Study efficacy of intraarticular analgesic injection.

2) Comparative between intra-articularanalgesic injection and femoral nerve block in patients who get total knee arthroplasty in Somdechphrapinklao hospital.

Hypothesis

Pain relief after total knee arthroplasty with intraarticular analgesic injection can relief pain; reduce amount of analgesic drug, ability of knee motion and hospital stay better than patients who received femoral nerve block.
Benefit

1) Guideline for patients who get Total knee arthroplasty received good analgesic drug for relief pain.

2) Study efficacy of intraarticular analgesic injection and femoral nerve block.

\section{Methods}

This is a quasi-experimental research. Control group equal characteristic with experimental group and two groups post-test only design

Population

Patient was severe osteoarthritis which does total knee arthroplasty at Somdechphrapinklao Hospital.

Inclusion Criteria

1) Patient was severe osteoarthritis which do got total knee arthroplasty.

2) Female age 60-70 years old.

3) Assign to attend research.

4) Do not previous surgery.

5) Surgery between Oct 2014 to Apr 2015.

Exclusion criteria

1) Patient was severe complication such as shock, severe anaphylactic shock, admitted ICU post.op and prolongs surgical time more than 2 hours.

2) Patients cannot take adequate data.

Samples

Taking female patients which the age between 60-70 years that have been diagnosed to be severe osteoarthritis and they have to do a total knee replacement on October 2014 to April 2015.

The patients were divided into 2 groups by systematic random sampling consists of:

1.Controlled group: Patient who got pain controlled drugs by injected in the femoral nerve block.

2. Experimentd group: Patient who got pain controlled drugs by intraarticular injection.

Equipment for research

A memo report for the patients after finished the total knee replacement surgery.

Part 1 General information: age, height, weight, BMI

(Body Mass Index) and congenital disease 
Part 2 Information after the surgery: pain level in 1, $3,6,12,24$ and 18 hours, using medicine in both injection and eating on the first, second and third day after the surgery, and flexion-extension degree on the fifth day

Examine for the function of the function of the equipment

Testing the content validity and objectivity of the questionnaire by 4 luminaries. $(\mathrm{ICO}=0.75)$

Researcher suggested the way to collect the data to anesthesiologist, nurse, officer research assistant nurse.

\section{Experiment}

Controlled group was injected the spinal morphine in $0.2 \mathrm{mg}$ before the surgery combine with injection $0.25 \%$ of marcaine $20 \mathrm{ml}$ to the femoral nerve block by the anesthesiologist. Experimented group was also injected the spinal morphine in $0.2 \mathrm{mg}$ before surgery combine with injection $0.25 \%$ of marcaine $20 \mathrm{ml}$ in the intraarticular injection by the surgeon. Using Visual Analog Score (VAS Score) to evaluate the pain level of the knee which 0 means without pain and 10 means the most painful. Both of these groups were taken NSAID (Naproxen) after the surgery. If VAS $=1-3$ and the patients needed, they were received Paracetamol 1,000 mg. On the other hand, if VAS was more than 3 and patients needed, they were received the injection of Tramadol $50 \mathrm{mg}$ instead. Both of these groups were received the continuous passive motion machine in the day after the surgery follow the clinical pathway and also measured the degree of motion every day.

\section{Results}

In this study, pain control method for the patients who have done the total knee replacement surgery can be done by the intraarticular injection and the femoral nerve block. The result shown that in 12 hours after the surgery, patients with the intraarticular injection method is painless than the femoral nerve block method. Moreover, flexion-extension degree of the knee in patient which intraarticular injection method is presented the significant better result compared with the femoral nerve block method as shown in Table 2 and 4.
Table 1. Patient demographic data of the intraarticular injection and the femoral nerve block.

\begin{tabular}{lccc}
\hline & IAI & FNB & $p$-value \\
& M(SD) & M(SD) & \\
\hline Population & 20 & 20 & \\
Age(Yrs. & $66(4)$ & $67(4)$ & 0.63 \\
Height $(\mathrm{Cm})$. & $159(8)$ & $158(7)$ & 0.188 \\
Weight(Kg.) & $69(17)$ & $63(9)$ & 0.505 \\
BMI $\left(\mathrm{Kg} / \mathrm{m}^{2}\right)$ & $27(5)$ & $25(4)$ & 0.266 \\
\hline
\end{tabular}

$\mathrm{IAI}=$ Intraarticular injection

FNB=Femoral nerve block

Table 2. Pain level comparison of the intraarticular injection and the femoral nerve block after the total knee replacement surgery.

\begin{tabular}{llll}
\hline Post.op time & $\begin{array}{c}\text { IAI } \\
\text { M(SD) }\end{array}$ & $\begin{array}{c}\text { FNB } \\
\mathrm{M}(\mathrm{SD})\end{array}$ & $p$-value \\
\hline $1^{\text {st }}$ hour & $1.9(0.7)$ & $2.2(0.8)$ & 0.307 \\
$3^{\text {rd }}$ hour & $2.8(0.8)$ & $2.9(0.6)$ & 0.657 \\
$6^{\text {th }}$ hour & $3.2(1.1)$ & $3.7(1.0)$ & 0.155 \\
$12^{\text {th }}$ hour & $2.9(1)$ & $4.2(1.2)$ & $0.001^{*}$ \\
$2^{\text {nd }}$ day & $3.1(0.9)$ & $3.6(1.2)$ & 0.150 \\
$3^{\text {rd }}$ day & $2.7(0.7)$ & $2.9(0.5)$ & 0.174 \\
\hline
\end{tabular}

$* p$ - value $<0.05$

IAI=Intraarticular injection

$\mathrm{FNB}=$ Femoral nerve block

Table 3. Comparison of injection analgesic drugs and taking analgesic medicine of the intraarticular injection and the femoral nerve block after the total knee replacement surgery.

\begin{tabular}{llll}
\hline Post-op. time & IAI & FNB & $p$-value
\end{tabular}

received $(\%)$ not received $(\%)$ received $(\%)$ not received $(\%)$

\begin{tabular}{|c|c|c|c|c|}
\hline \multicolumn{5}{|c|}{ Tramal $50 \mathrm{mg}$ iv } \\
\hline $1^{\text {st }}$ day & $4(20) 16(80)$ & $8(40)$ & $12(60)$ & 0.176 \\
\hline $2^{\text {nd }}$ day & $6(30) 14(70)$ & $9(45)$ & $11(55)$ & 0.34 \\
\hline $3^{\text {rd }}$ day & $3(15) 17(85)$ & $3(15)$ & $17(80)$ & 1.00 \\
\hline
\end{tabular}


Post-op. time IAI FNB $p$-value

received $(\%)$ not received $(\%)$ received $(\%)$ not received $(\%)$

Paracetamal 1000mg.

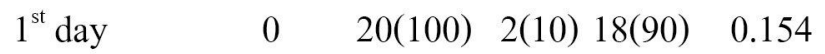

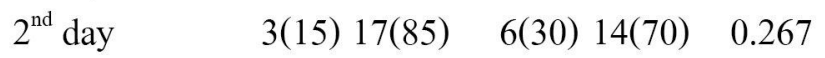

$\begin{array}{llllll}3^{\text {rd }} \text { day } & 1(5) & 19(95) & 0 & 20(100) & 0.324\end{array}$

IAI=Intraarticular injection

$\mathrm{FNB}=$ Femoral nerve block

Table 4. Comparison of number of the day that patients stay in the hospital and ability of flexion extension of knee of the intraarticular injection and the femoral nerve block after the total knee replacement surgery.

\begin{tabular}{cc}
\hline IAI & FNB $p$-value \\
M(SD) & M(SD) \\
\hline
\end{tabular}

Hospital stay(day) $\quad 7.3(1.3) \quad 8.2(1.8) \quad 0.062$

Flexion of knee(degree) 104.5(7.6) 95(12.8) $0.007^{*}$

$* p$ - value $<0.05$

IAI=Intraarticular injection

$\mathrm{FNB}=$ Femoral nerve block

\section{Discussion}

According to the research, pain control result by using intraarticular injection method is present the significant great result compare with femoral nerve block method by 0.05 statistical. According to Ashraf's research and team ${ }^{(12)}$ and $\mathrm{Fu}$-Yuen Ng and team. ${ }^{(13)}$ Due to during total knee replacement surgery, tissue injury has neurological respond 2 ways consist of peripheral sensitization that increase sensitivity of nociceptive receptor and central sensitization that increase sensitivity of spinal nervous. Intraarticular injection method can reduce central and peripheral sensitization, thus patients have VAS score less than femoral nerve block ${ }^{(14)}$ and intraarticular injection method shows the average of pain less than femoral nerve block method. The result shows that intraarticular injection method has more effectively than femoral nerve block according to research of Lamplot JD and team ${ }^{(4)}$ Vendittoli PA and team. ${ }^{(5)}$
In 3, 6, 24, 48 hours after surgery, intraarticular injection method shows that there is no different of pain compare with femoral nerve block according toTanikawa $\mathrm{H}$ and team. ${ }^{(7)}$

After surgery for 5 days, the 90 degrees knee flexion of patient who gets intraarticular injection is better than patient who gets femoral nerve block because femoral nerve comes from spinal level L2-L4 to quadriceps muscle and receive sensation from front and inside of thigh but the muscle beside and back of thigh receive sensation by sciatic nerve that comes from spinal level L4-S3. ${ }^{(8)}$ So, femoral nerve block method not cover beside and back muscle of thigh that affect to flexion and extension knee of patient according to Peiliang Fu and team ${ }^{(4)}$, Tanaka and team ${ }^{(15)}$ and Antoni and team. ${ }^{(16)}$

\section{Conclusion}

The intraarticular injection shows a better result in flexion of knee and factor affecting the pain is in line with Toftdahlk and team's research that present effective in reduce pain after surgery and rapidity in rehabilitation of knee.

\section{Suggestion}

The intraarticular injection during operation can reduce analgesic after the operation and flexion of knee better than femoral nerve block. Both methods can reduce analgesic after operation and show good recovery. This research can be a guideline for appropriate and sufficient pain reducing in total knee replacement surgery.

\section{Suggestion for next research}

1) Should have studied the effectiveness of sciatic nerve block in conjunction with the injection into the femoral nerve block in patients who received total knee replacement surgery.

2) Should have studied the effectiveness of continuous intraarticular injection for relieving pain of patients who received total knee replacement surgery.

\section{References}

1. Clinical practice guideline of osteoarthritis 2011. Royal College of Orthopaedic Surgeons of Thailand. www.rcost.or.th 
2. Chaiamnuay P, Darmawan J, Muirden KD,Assawatanabodee P. Epidemiology of rheumaticdisease in rural Thailand: a WHO-ILAR COPCORD study. Community Oriented Programme for the Control of Rheumatic Disease. J Rheumatol 1998; 25: 1382-7.

3. Kuptniratsaikul V, Tosayanonda O, Nilganuwong S, Thamalikitkul V. The epidemiology ofosteoarthritis of the knee in elderly patients living an urban area of Bangkok. J Med Assoc Thai 2002; 85: 154-61.

4. Lamplot JD, Wagner ER, Manning DW. A multimodal pain management in total knee arthroplasty: a prospective randomized controlled trial. J Arthroplasty 2014; 29: 329-34.

5. Vendittoli PA, Makinen P, Drolet P, Lavigne M, Fallaha M, Guertin MC. A multimodal analgesia protocal for total knee arthroplasty. A randomized, controlled study. J Bone Joint Surg Am 2006; 88: 282-9.

6. Toftdahl K, Nikolajsen L, Haraldsted V, Madsen F, Tønnesen EK, Søballe K. Comparison of peri and intraarticular analgesia with femoral nerve block after total knee arthroplsty. A randomised clinical trial. Acta Orthop 2007; 78: 172-9.

7. Tanikawa H, Sato T, Nagafuchi M, Takeda K, Oshida J, Okuma K. Comparison of local infiltration of analgesia and sciatic nerve block in addition to femoral nerve block for total knee arthroplasty. J Arthroplasty 2014; 29:2462-7.

8. Szczukowski M J, Hines J A, Snell JA, Sisca TS. Femoral nerve block for total knee arthroplasty patients: a method to control postoperative pain. J Arthroplasty 2004; 19: 720-5.

9. Widmer BJ, Scholes CJ, Pattullo GG, Oussedik SI, Parker DA, Coolican MR. Is femoral nerve block necessary during total knee arthroplasty?: A randomized control trial. J Arthroplasty 2012; 27: 1800-5.

10. Yuenyongviwat $\mathrm{V}$, Chinachoti $\mathrm{T}$, Chareancholvanich $\mathrm{K}$, Chareancholvanich K. Periarticular injection with bupivacaine for postoperative pain control in total knee replacement. A prospective randomized double-blind controlled trial. Adv Orthop 2012: 2012: 107309.

11. Panichkul $P$, Yakumpor $T$, Tammachote $N$, et al. Is pain after TKA better with periarticular injection or intrathecal morphine? Clin Orthop Relat Res 2013; 471: 1992-9.

12. Ashraf A, Raut V, Canty S, et al. Pain control after primary total knee replacement. A prospective randomised controlled trial of local infiltration versus single shotfemoral nerve block. The Knee 2013; 20: 324-7.

13. Fu-Yuen Ng, Jacobus K, Kwong-Yuen C, et al. Multimodal periarticular injection Vs continuous femoral nerve block after total knee arthroplasty. A prospective, crossover, randomized clinical trial. J Arthroplasty 2012; 27: 1234-8.

14. Peiliang F, Yuli W, Haishan W, et al. Efficacy of intra-articular cocktail analgesic injection in total knee arthroplasty. A randomized controlled trial. The Knee 2009; 16: 280-4.

15. Tanaka N, Sakahashi H, Sato E, et al. The efficacy of intra-articular analgesic after total knee arthroplasty inpatients with rheumatoid arthritis and in patients with osteoarthritis. J Arthroplasty 2001; 16: 306-11.

16. Antoni M, Jenny J, Noll E, et al. Postoperative pain control by intra-articular local analgesia versusfemoral nerve block followingtotal kneearthroplasty. Impact on discharge. Orthopaedics \&Trauma: Surgery\&Research 2014;100: 313-6. 